\title{
Reseña de: R. Lucas Platero, María Rosón y Esther Ortega (eds.). Barbarismos queer y otras esdrújulas. Barcelona: Bellaterra, 2017.
}

\section{Gema CALERo LóPeZ}

La obra Barbarismos queer y otras esdrújulas es una suerte de diccionario de lenguaje queer y feminista que propone la definición de 53 términos. Está escrita en contribución por al menos 55 personas, cada una de las cuales ha desarrollado una o varias entradas partiendo de su conocimiento en ese ámbito o desde una aproximación a partir la convergencia de materias relacionadas con el sustantivo en cuestión. Es un privilegio, por tanto, contar con el trabajo de autoras como Raquel Osborne, Javier Sáez, Carmen Romero, Fefa Vila, Melania Moscoso, Jokin Azpiazu, Rebeca Ibáñez, Brice Chamouleau, Dau García Dauder, Robert McRuer, Virginia Villaplana o Lucía Egaña, entre otras, que nos adentran en realidades diversas presentadas desde una perspectiva basada en la experiencia y el conocimiento profundo de cada área, potenciando el valor de la obra gracias al origen multidisciplinar de las autoras.

La edición de la obra se produce igualmente de manera colaborativa mediante el trabajo de R. Lucas Platero, María Rosón y Esther Mayoko Ortega. Lucas Platero Méndez es doctor en Sociología y Ciencias Políticas, profesor de Intervención Sociocomunitaria y colaborador en varios másteres, activista y autor o co-autor de obras en relación con la interseccionalidad, políticas públicas en torno a sexualidades no normativas y personas trans*, propuestas educativas y herramientas para combatir el bullying LGTBIQfóbico, así como investigaciones sobre personas trans* en contextos escolares y familiares. En cuanto a María Rosón Villena, es doctora por la Universidad Autónoma de Madrid con un trabajo realizado en torno a la construcción visual de identidades en la España franquista. Forma parte del departamento de Teoría de los Lenguajes y las Ciencias de la Comunicación de la Universidad de Valencia, 
ha participado en trabajos relacionados con la construcción de identidad a través de fotografías y construcción de la cultura contemporánea, entre otros, y es autora del libro Género, memoria y cultura visual en el primer franquismo. La tercera editora es Esther Mayoko Ortega Arjonilla, doctora en Filosofía de la Ciencia, especializada en Ciencia, tecnología y sociedad, Tecnociencia Postcolonial así como en Estudios feministas y queer relacionados con la Biomedicina. Ha sido co-editora de la presente obra y de Biopolíticas de la ciencia y la tecnología y también es activista feminista antirracista, participando en el Espacio Afroconciencia.

Existen obras previas en las que se recoge cierta cantidad de terminología LGTBIQ+ como los diccionarios gay-lésbicos de Mira, Éribon o Félix Rodríguez, así como artículos de varia índole, como el de Diana J. Torres, en el que, por ejemplo, se propone un acercamiento al concepto bonobo desde la etimología y las prácticas sociales. Pero a pesar de los compendios, puede decirse que el trabajo que aquí se comenta es una obra pionera en la compilación en lengua castellana de tal cantidad de terminología queer, desarrollada además con precisión y profundidad, especialmente con la intención de reflejar los debates existentes y no ofrecer definiciones prescriptivas. Aparece en una época en la cual los neologismos fluyen rápidamente gracias a una lógica geopolítica concreta, y dado que las prácticas subjetivas forman parte del significado de los términos, este es un trabajo necesario tanto para la teoría como para la práctica queer situada.

Hemos de partir de la premisa de que el contexto es parte esencial del uso y de la conformación del significado de una palabra. La conectividad entre la lengua y el contexto hace que, por mímesis, esta primera adquiera el dinamismo necesario para ser modificada y reapropiada mediante una diversidad de prácticas, tanto en la academia como fuera de ella, en constante emergencia y contradicción. Encontramos un ejemplo de ello en la problematización del calificativo "discapacidad", que ha estado en el centro del debate, y parte del colectivo social propone sustituirlo por un término autoelegido y menos capacitista, "diversidad funcional", superando con ello algunas de las categorizaciones sociales, jurídicas y médicas patologizantes asociadas al lenguaje de la "capacidad".

Igualmente, si observamos la adaptación y el uso de los barbarismos en los territorios hispanohablantes, encontramos también ejemplos de ello, pues 
tanto en América Latina y el Caribe como en el estado español una diversidad y riqueza de lenguas y dialectos atraviesan este léxico político. De esta forma, pueblos, grupos sociales y comunidades llevan constantemente a cabo una construcción y adaptación propia de los neologismos aquí estudiados, como es el caso de cuir, queer y cuy $(r)$.

También es necesario recordar que hay entornos en los que existe una resistencia explícita a la introducción y al uso de aquellos términos acuñados en países con prácticas culturales, económicas y políticas neocoloniales. Esto es algo que forma parte del sentimiento de superioridad colonialista por una parte y, paralelamente, de una estrategia política implícita mediante la manipulación del lenguaje. De esta forma encontramos un freno al avance global del la lengua junto con una oposición al uso y a la aceptación de términos anglosajones (lo cual resulta incongruente considerando este devenir socio-político generalizado desde los entramados del poder que persiguen la globalización a gran escala). En cuanto a la fuerte manipulación terminológica a nivel político, cabe señalar la gran afluencia del uso de eufemismos y expresiones que ocultan, mediante el vaciamiento de los conceptos, las propuestas y críticas que estos emanan. En este sentido, las reformas de la ley educativa resultan un caso paradigmático: en la Ley Orgánica de Educación y la Ley Orgánica de Mejora de la Educación, se articulan conceptos como "el pacto educativo", "el emprendimiento", "la excelencia" o "la autonomía de los centros" como claro ejemplo de la utilización de una terminología asociada a valores aceptados por una gran parte del sentido común histórico para promover medidas de estructuración de la producción de desigualdad social.

Y en esta época en la que, tanto desde la teoría como desde la práctica social, la función performativa del lenguaje está siendo estudiada y apropiada, y en donde, al mismo tiempo, la lógica global de dicho fenómeno crítico forma parte de una racionalidad occidental hegemónica, nace esta obra para reivindicar nuestras disidencias y formas concretas de hacer vida. Y es que el libro engloba detallada, clara y concisamente una amalgama de vocablos, explicados desde la etimología, la historia y su evolución, poniendo siempre sobre la mesa la diversidad como constitutiva del lenguaje.

El hecho de que cada entrada esté producida por distintas autoras aporta una gran riqueza de estilo, creando un conjunto de saberes colectivos como analogía de la sociedad en la que vivimos, un formato que apuesta por la

Feminismo/s 31, junio 2018, pp. 253-256 
colectividad y el ensamblaje de los saberes. Y por esa misma razón esta heterogeneidad presenta también una discontinuidad de estructura. Mientras que en algunas entradas disfrutamos de análisis complejos en donde se llega incluso a pensar los vocablos en relación a castellanos de diversas latitudes, a lenguas como el gallego, el catalán o el euskera y a sus usos por regiones, en otras el acercamiento al término es mucho más general o reducido a un contexto, a una evolución y a una práctica histórica casi exclusivamente local.

La obra goza de una extensión considerable que, aun requiriendo un buen tiempo de lectura, invita ávidamente a sumergirse en ella. Al situarse en uno de los ejes centrales del debate feminista y queer contemporáneo, sobre la resistencia en época de las políticas neoliberales pinkwashed, resulta un trabajo esencial. Así, considero ésta una lectura ampliamente útil para la articulación de un discurso que haga frente al lenguaje político que, no solo no nos representa, sino que además nos produce, norma y excluye según su propia racionalidad.

¿Para cuándo un Más barbarismos queer y nuevas esdrújulas?. 